\title{
Who is to Blame?
}

\section{A Case of Medical Negligence in Obstetrical Care}

Erica Hoe (Meds 2016)

Faculty Reviewer: Dr Ellen Tsai, MD, MHSc (Bioethics), FRCPC (Canadian Medical Protective Association)

\section{CASE SUMMARY}

A 30-year-old nulliparous pregnant female presents to a large urban teaching hospital at 35 weeks gestation in active labour following spontaneous membrane rupture. She is initially assessed by her obstetrician, who after assessing the fetal heart rate to be normal and reactive, prescribes oxytocin by infusion to augment her contractions. The patient is then followed by both the obstetrician and a junior obstetrics resident.

The obstetrician reassesses the patient several hours later and orders the oxytocin infusion to be increased because the contractions are only moderately strong. Epidural anesthesia is initiated by an anesthesiology resident prior to increasing the oxytocin. The nurse then calls the obstetrics resident to reassess the patient, following an episode of fetal bradycardia lasting several minutes-a possible indicator of impaired fetal oxygenation-subsequent to the epidural insertion. The resident places a fetal scalp electrode to monitor the heart rate more accurately, which demonstrates decreased heart rate variability and variable decelerations. The nurse expresses concern to the resident when the variable decelerations persist. The resident then calls the obstetrician to recommend monitoring the patient a little longer because the cervix is already 8-9 cm dilated, rather than proceeding directly to a Cesarean section. The obstetrician accepts the resident's plan without reviewing the fetal heart rate tracing.

Within the hour, the patient's cervix is fully dilated and the resident instructs the patient to begin pushing. The obstetrician arrives shortly thereafter. Upon delivery of the infant's head, the umbilical cord is found to be wrapped tightly around the neck and thus is cross-clamped and cut. The baby boy is then delivered easily and spontaneously, but is pale and flaccid with gasping respirations immediately after birth.

The obstetrics resident and nurses begin resuscitation of the infant. The infant's colour becomes pink within one or two minutes, but his tone remains flaccid. The anesthesiology resident is paged, intubates the infant at 10 minutes of life, and manages the resuscitation until the arrival of the on-call pediatrician at 45 minutes of life. The infant is subsequently transferred to a tertiary care neonatal unit, where he is diagnosed with hypoxic brain injury, eventually resulting in severe quadriplegic cerebral palsy, cortical blindness and recurrent seizures.

A legal action follows some years later.

\section{NEGLIGENCE IN MEDICAL PRACTICE}

This real-life case illustrates the complexity of medico-legal actions, where there are often several physicians-and other health professionals-involved in the patient's care. The court found the care of both the attending obstetrician and the obstetrics resident in this case to be negligent. Negligence is determined when the patient-plaintiff can prove on the balance of probabilities that the physician had a duty of care, and that the harm experienced was as a result of a breach of the standard of care. ${ }^{1}$ The standard of care is based on what a normal, prudent physician of similar training and experience would do in similar circumstances. ${ }^{2}$ Courts will judge whether the standard of care was breached after considering the testimony of physician peers, otherwise referred to as medical experts. ${ }^{3}$ This case illustrates how the standard of care is determined differently for each physician, based on their level of training and the particular clinical circumstances.

The attending obstetrician breached the standard of care on several counts. The primary criticism was that he did not call the pediatrician earlier. As such, the obstetrician failed to display situational awareness. Although physicians are not expected to accurately predict outcomes, they have the responsibility to anticipate critical situations that may arise and act according to what a reasonably prudent physician would be able to foresee. There were several risk factors present-including prematurity and abnormal fetal heart rate tracings-that should have mandated a request for pediatric attendance at delivery based on the national practice standards in place at that time. ${ }^{4}$

The obstetrics resident's actions also fell below the standard of care in this case. The court determined that a reasonably prudent resident at the same level of training should have been able to recognize the warning signs of fetal distress and alert the attending obstetrician sooner. Medical trainees, including medical students, are responsible for knowing the limits of their own knowledge and experience. Similar to the staff obstetrician, the resident failed to recognize the significance of the abnormal fetal heart rate tracing and subsequently the gravity of the infant's condition after birth.

Another criticism of the obstetrician was in regard to supervision of the resident. Supervising physicians can reasonably rely upon residents to carry out the duties properly delegated to them; however, they must be aware of circumstances when more active supervision is required. This will depend on such factors as the patient's condition, the complexity of the procedure, and the level of experience and skill of the resident. Failure to adequately supervise a trainee can result in liability for the supervising physician, even if the harm was caused by the trainee's actions.

The resident did not alert the attending obstetrician to persistent fetal heart rate abnormalities in a timely manner. Nevertheless the obstetrician was still responsible for overseeing the overall 
care of the patient, including the resident's work. In this case, the obstetrician overly relied on the skills and knowledge of this junior resident, and did not personally review the abnormal fetal heart rate tracing. The principle of shared responsibility is reflected in the court's apportionment of liability, which in the end was $75 \%$ for the attending obstetrician and $25 \%$ for the obstetrics resident.

Interestingly, the anesthesiology resident was not found to be negligent and was dismissed from the legal action. As a first-year resident who was in the third month of a pediatric anesthesia block, this resident would have had limited experience in the care of premature neonates at the time of the events. Any contribution to the infant's outcome was considered to be negligible; in fact, it was the anesthesiology resident who called for the pediatrician's help and managed the resuscitation to the best of his abilities until the pediatrician's arrival.

\section{DISCUSSION}

Even when physicians have strived to provide the best possible care, harm to the patient can ensue. On review of this case, it is easy to identify actions that could have led to a better outcome. However, these actions may not have been as obvious at the time. This is called hindsight bias, and it is comforting to know that the Courts do consider it when adjudicating cases of alleged medical negligence. ${ }^{5}$

The inability to predict the occurrence of a legal action may lead some physicians to practice "defensive medicine". Defensive medicine refers to making clinical decisions based on fear of litigation rather than on the clinical needs and the best interests of the patient. Thus defensive medicine is not good medicine. Instead, physicians should practice medicine according to evidence-based or peer-reviewed standards and implement risk management techniques. Consulting colleagues in uncertain situations, appropriately applying current clinical practice guidelines and documenting the rationale for one's decisions can all improve a physician's defensibility.

Finally, as medical trainees, we should know the limits of our knowledge and experience. It is expected that we will be given greater responsibility and autonomy with increasing training and experience. The Courts have previously commented that it makes intuitive sense to have residents gradually left more on their own over the course of training. But it also means that we should not be afraid to ask for help. In failing to contact our supervisor, or to consult colleagues and other trusted resources, not only may the patient be harmed, but we may also be held legally liable for our actions.

During my summer internship at the Canadian Medical Protective Association (CMPA), these were just a few of the key lessons that I learned. If you want to learn more about ways you can promote safe medical care, visit the CMPA Good Practices Guide at www.cmpa-acpm.ca/gpg or just ask me for more information!

\section{REFERENCES}

1. Picard EI, Robertson GB. Legal liability of doctors and hospitals in Canada. 4th ed. Toronto: Thompson Carswell; 2007. 212 p.

2. Ibid., $227 \mathrm{p}$.

3. Canadian Medical Protective Association. Clinical practice guidelines: what is their role in legal proceedings? [Internet] Version 09.11. Ottawa, Canada: Canadian Medial Protective Association; 2011 [cited 2014 Oct 19] Available from: https:// oplfrpd5.cmpa-acpm.ca/en/legal-and-regulatory-proceedings/-/asset_publisher/a9unChEc2NP9/content/clinical-practice-guidelines-what-is-their-role-in-legal-proceedings-.

4. Chow (Litigation guardian of) v. Wellesley Hospital [1999] O.J. No. 279. Available from: http://www.sommersandroth.com/ wp-content/themes/sommers/pdf/Chow-v-Wellesley-Hospital.pdf.

5. Canadian Medical Protective Association. Foreseeability: what is expected of a physician? [Internet] Ottawa, Canada: Canadian Medical Protective Association; 2009 [cited 2014 Oct 19] Available from: https://oplfrpd5.cmpa-acpm.ca/en/ legal-and-regulatory-proceedings/-/asset_publisher/a9unChEc2NP9/content/foreseeability-what-is-expected-of-a-physician-. 